\title{
Seguimiento mediante prueba de ELISA para anticuerpos IgE de pacientes con equinococosis quística tratados con albendazol
} Follow-up of human cystic echinococcosis by IgE antibodies after albendazole treatment

\author{
Herman Vildózola Gonzales¹, Irma Espinoza Blanco', Willy Roldán Gonzales', \\ Susana Jiménez Ramírez', Minorka Nicho Póvez², Grobert Mendoza², \\ Edgardo Meza Astuvilca² \\ 1 Instituto de Medicina Tropical «Daniel A. Carrión», Universidad Nacional Mayor de San Marcos, Lima, Perú. \\ ${ }^{2}$ Departamento Académico de Medicina, Facultad de Medicina, Universidad Nacional Mayor de San Marcos, Lima, Perú.
}

\begin{abstract}
Resumen
Antecedentes. En un estudio previo, los autores estandarizaron una prueba de ELISA IgE para hidatidosis con alta sensibilidad $(95,6 \%)$ y especificidad $(100 \%)$ para el diagnóstico y seguimiento de pacientes tratados con albendazol, con resultados alentadores. Objetivo. Confirmar la utilidad de la medición de los niveles de los anticuerpos IgE en pacientes con equinococosis quística tratados con albendazol y considerados curados clínica y ecográficamente y en pacientes mejorados o curados que recurrieron. Diseño. Estudio retrospectivo-prospectivo, de tipo cuasi experimental, corte longitudinal, con pre prueba y post prueba en un solo grupo para evaluar el diagnóstico y seguimiento en los casos prospectivos y el seguimiento y recurrencia en ambos grupos. Institución Instituto de Medicina Tropical "Daniel A. Carrión", Universidad Nacional Mayor de San Marcos, Lima, Perú. Participantes. Pacientes con equinococosis quistica. Métodos. Se incluyó 17 pacientes, 15 mujeres y 2 hombres, entre 25 y 80 años de edad (promedio 58 años), con uno más quistes hepáticos y en uno además quistes pulmonares; 16 fueron tratados con albendazol a la dosis de $12-15 \mathrm{mg} / \mathrm{kg}$, en 3 a 5 ciclos de 28 días y uno recibió tratamiento con albendazol y cirugía por una complicación. Todos fueron seguidos entre dos y 12 años postratamiento, con evaluación clínica y ecográfica en 2 a 7 oportunidades y cuantificación de los niveles de anticuerpos IgE para equinococosis en muestras de sangre. La técnica utilizada para la detección de anticuerpos IgE mediante prueba de ELISA para IgE fue estandarizada por los autores. Principales medidas de resultados. Relación de niveles de anticuerpos IgE en sangre y comportamiento de la enfermedad. Resultados. En 10 de los 17 pacientes se mantuvieron los niveles de IgE por debajo del punto de corte, lo que se consideró como evidencia de curación, lo que además coincidia con los cambios en la ecoestructura que iba de CE1 y CE2 a CE4 y CE5, según la clasificación de la OMS para las imágenes ultrasonográficas, y que significan en los primeros alta actividad y en los últimos actividad baja o nula. Siete pacientes que al final del tratamiento mostraron evidencia de curación o gran mejoría clínica y ultrasonográfica y cuyos niveles de lgE descendieron de manera significativa, en algunos por debajo de los niveles de corte, presentaron incremento sostenido de estos niveles como expresión de recurrencia o de aparición de nuevos quistes. Conclusiones. La prueba de ELISA para la detección de anticuerpos IgE de equinococosis quística estandarizada por los autores demostró ser una prueba útil para el seguimiento del tratamiento con albendazol, de manera de confirmar la curación clínica y ultrasonográfica de la equinococosis quística hepática. También aparece útil para la detección temprana de las recurrencias de los pacientes curados o con marcada mejoría.
\end{abstract}

Palabras clave. Anticuerpos IgE; Prueba ELISA; Equinococosis; Albendazol.

\section{Abstract}

Background: In a previous study an IgE ELISA test for hydatidosis was standardized and evidenced high sensitivity (95.6\%) and specificity (100\%) and encouraging results for the diagnosis and follow up of patients treated with albendazole. Objectives: To confirm efficacy of IgE antibody level determination in patients with cystic echinococcosis treated with albendazole and considered clinically cured and ultrasonographically improved, or recurrence in patients considered improved or cured. Design: Longitudinal, retrospective-prospective, quasi-experimental study, longitudinal study, with pre- and post-test for assessing diagnosis and monitoring in the prospective group, and follow-up and recurrence in both groups. Setting: Instituto de Medicina Tropical "Daniel A. Carrión", Universidad Nacional Mayor de San Marcos, Lima, Peru. Participants: Patients with cystic echinococcosis. Methods: Seventeen patients, 15 female and 2 male, 25-80 years old (average 58 years) carrying one or more hepatic cysts and one also lung cysts were treated with albendazole $12-15 \mathrm{mg} / \mathrm{kg}$ in 3 or 528 -day cycles. One had also surgical treatment for a complication. They were followed for 2 to 12 years after treatment, with clinical and ultrasound evaluation 2-7 times and serum quantification of echinococcosis IgE antibody levels. IgE antibody detection method was IgG ELISA test standardized by the authors. Main outcome measures: Relation of serum IgE antibodies and disease outcome. Results: Out of the 17 patients, 10 had serum IgE below cutoff levels considered as evidence of healing. This coincided with eco structural changes from CE1 and CE2 to CE4 and CE5, according to the ultrasound imaging WHO classification, indicating high activity in the firsts and low or no recent activity in the latter. Seven patients evidencing cure or clinical and ultrasound improvement and significant decrease of $\mathrm{lg} E$ some below de cut-off level showed sustained increase of these levels expressing recurrence or appearance of new cysts. Conclusions: ELISA test for cystic echinococcosis IgE antibodies detection standardized by the authors appears as a useful tool for albendazole treatment follow-up in order to confirm clinical and ultrasound cure of liver cystic echinococcosis. It seems also useful for early detection of recurrences in patients cured or markedly improved.

Keywords: IgE antibodies; Enzyme-linked immunosorbent assay; Echinococcosis; Albendazole.

An Fac med. 2015;76(3):241-6 / http://dx.doi.org/10.15381/anales.v76i3.11231 


\section{INTRODUCCIÓN}

La equinococosis quística (EQ), causada por larvas de Echinococcus granulosus, es una zoonosis parasitaria que constituye un serio problema de salud pública en muchas regiones del mundo ${ }^{(1)}$. En Sudamérica existe en varios países, entre los cuales se encuentra nuestro país, especialmente en zonas de la sierra ${ }^{(2-4)}$.

Esta enfermedad es usualmente diagnosticada mediante exámenes clínicos utilizando diferentes técnicas de imágenes y pruebas inmunológicas para la detección de anticuerpos séricos específicos contra el parásito. La sensibilidad y especificidad de las diferentes pruebas inmunoserológicas dependen de la etapa de la enfermedad, la localización de los parásitos, los antígenos y las técnicas utilizadas ${ }^{(5-7)}$.

La terapia de la equinococosis quística es primariamente quirúrgica. En nuestros días además se cuenta con alternativas terapéuticas como el tratamiento no convencional percutáneo guiado ultrasonográficamente (PAIR: punción, aspiración, inyección de sustancia escolicida y reaspiración) y el tratamiento farmacológico con benzoimidazol carbamatos y la termoablación con radiofrecuencia como alternativas eficaces ${ }^{(8,9)}$.

En las tres últimas décadas, el tratamiento de la equinococosis quística ha mejorado marcadamente, gracias a la introducción del albendazol y el mebendazol; estos dos benzimidazoles han facilitado el manejo efectivo de pacientes que no hubiesen podido ser fácilmente curados por la cirugía, como aquellos con quistes múltiples, compromiso multiorgánico, quistes secundariamente diseminados o rotos intraoperatoriamente y aquellos con contraindicaciones para la cirugía ${ }^{(10,11)}$.

Una serie de informes recientes demuestran el valor potencial que posee el análisis de anticuerpos de las subclases del IgG para el serodiagnóstico específico de la equinococosis quística (EQ) o para estudios de seguimiento después de la cirugía o después de la quimioterapia ${ }^{(1,12-16)}$. Uno de los problemas con las subclases de $\operatorname{IgG}$ es su limitación para correlacionarse en forma positiva con la evolución postoperatoria del paciente o la respuesta al tratamiento médico con albendazol ${ }^{(5,13-15)}$, constituyendo un obstáculo para afirmar la curación en aquellos casos en que la respuesta aparente al tratamiento con albendazol ha sido catalogada como éxito terapéutico. $\mathrm{Al}$ respecto, ha sido muy importante la clasificación de la OMS ${ }^{(17)}$ de los quistes hidatídicos, que permite estandarizar los diferentes momentos de su evolución y correlacionar estos hallazgos con su actividad clínica, la cual decrece desde los tipos CE1 CE2 -que son los más activos- al CE5, que representa la lesión parasitaria más inactiva; sin embargo, en la práctica no siempre es posible encontrar esta concordancia entre la imagen ultrasonográfica y el grado de actividad. En estos casos, el estudio inmunoserológico podría representar el complemento ideal para aclarar si la imagen quística está activa o no.

En ese sentido, algunos autores han encontrado que el dosaje de IgE sérica total o la detección de anticuerpos IgE parecen correlacionarse con la evolución postoperatoria o con la respuesta al tratamiento médico ${ }^{(18-22)}$.

En un estudio reciente ${ }^{(23)}$ comunicamos la estandarización de una prueba de ELISA para anticuerpos IgE de equinococosis, donde comprobamos su sensibilidad $(95,6 \%)$ y especificidad (100\%) para el diagnóstico, seguimiento y detección temprana de la recurrencia en equinococosis quística. En esa pequeña muestra de pacientes se encontró que el dosaje de IgE total sérica o la detección de anticuerpos IgE parecen correlacionarse con la evolución postoperatoria o con la respuesta al tratamiento médico, como se demostró en otros estudios ${ }^{(24,25)}$.

El objetivo del presente estudio fue confirmar la utilidad de la medición de los niveles de los anticuerpos IgE en pacientes con equinococosis quística tratados con albendazol y que se consideraron curados clínica y ultrasonográficamente, así como detectar precozmente las recurrencias postratamiento.

\section{METODOLOGÍA Y TÉCNICAS DE INVESTIGACIÓN UTILIZADAS}

En el presente estudio se incluyó 17 pacientes -15 mujeres y 2 hombres- con edades entre 25 y 80 años (promedio 58 años), tratados con albendazol en 16 casos y uno con albendazol y cirugía por una complicación. Todos fueron seguidos entre dos y 12 años después del tratamiento. Se les evaluó clínica y ultrasonográficamente 2 a 7 veces postratamiento y se tomó una muestra de sangre para la cuantificación de los niveles de anticuerpos IgE para equinococosis.

Todos los pacientes fueron tratados con albendazol a la dosis de $12-15 \mathrm{mg} /$ $\mathrm{kg}$ de peso por día, en tres ciclos de 28 días, con intervalos de 14 días sin tratamiento entre cada ciclo; recibieron como mínimo tres ciclos y máximo cinco ciclos.

El estudio fue retrospectivo-prospectivo, de tipo cuasi experimental, de corte longitudinal, con pre prueba y post prueba en un solo grupo para evaluar el diagnóstico y seguimiento en los casos prospectivos y seguimiento y recurrencia en ambos grupos.

Doce pacientes fueron diagnosticados con Western blot bandas 8, 16, 21 y seguidas postratamiento con ELISA IgE; 5 pacientes fueron diagnosticados y seguidos postratamiento con ELISA $\mathrm{IgE}$.

La técnica utilizada en la detección de los anticuerpos IgE fue descrita en otro estudio de los autores publicado recientemente ${ }^{(23)}$ y que consta de los pasos presentados a continuación.

El contenido proteico de los antígenos fue realizado según el método de Lowry y colaboradores ${ }^{(22)}$. Para la semipurificación del antígeno B, el líquido hidatídico de quistes (HCF) de E. granulosus fue obtenido a partir de 
quistes hidatídicos pulmonares o hepáticos de origen ovino procedentes de un camal local. Estos líquidos fueron dejados sedimentar y el sobrenadante fue centrifugado a $4000 \mathrm{rpm}$ durante 10 minutos. Posteriormente, el líquido fue concentrado y luego el antígeno B (AgB) fue purificado, siguiendo la metodología descrita por Oriol y colaboradores ${ }^{(26)}$. El contenido proteico del AgB fue realizado según el método de Lowry y colaboradores ${ }^{(22)}$.

Las microplacas de poliestireno fueron sensibilizadas con $\mathrm{AgB}$ a una concentración de $2 \mu \mathrm{g} / \mathrm{mL}$ en buffer carbonato, $\mathrm{pH} 9,6$, durante 18 horas a $4^{\circ} \mathrm{C}$. Las microplacas fueron lavadas brevemente con buffer fosfato salino (PBS, pH 7,2) y luego bloqueadas con una solución de albúmina sérica bovina al $1 \%$ en PBS conteniendo Tween 20 al 0,05\% (PBS-T), durante 2 horas a 37 ${ }^{\circ} \mathrm{C}$. A continuación, las microplacas fueron lavadas, secadas y guardadas a $-20^{\circ} \mathrm{C}$ hasta su posterior uso.

Con el objetivo de incrementar la detección de los anticuerpos IgE, cada muestra de suero a ser testado fue previamente tratado con anticuerpos de carnero anti-IgG humano (RF Absorbent, Siemens Healthcare, USA) a una dilución de 1/20 para la eliminación de los anticuerpos IgG; la mezcla fue incubada a $4^{\circ} \mathrm{C}$ durante toda una noche y luego centrifugada a $10000 \mathrm{rpm}$ por 10 minutos. El sobrenadante resultante fue utilizado para la detección de anticuerpos $\operatorname{IgE}$.

Se adicionó un volumen de $100 \mu \mathrm{L}$ en cada pocillo de las muestras tratadas y de los controles positivos y negativos, y luego se incubó toda una noche a $37^{\circ} \mathrm{C}$. Al día siguiente, las placas fueron lavadas 3 veces por 5 minutos con PBS-T y luego incubadas con una solución de anticuerpo anti-IgE humano conjugado con peroxidasa (SigmaAldrich, USA), diluido 1/4 000 durante 1 hora a $37^{\circ} \mathrm{C}$. A continuación, las placas fueron lavadas como ya fue descrito anteriormente y luego se adicionó una solución de substrato-cromógeno (OPD-Fast, Sigma-Aldrich, USA) y se incubó durante 30 minutos a $37^{\circ} \mathrm{C}$. Finalmente, la reacción enzimática fue detenida por adición de ácido sulfúrico $2,5 \mathrm{~N}$. Las placas fueron analizadas en un lector de ELISA a una longitud de onda de $490 \mathrm{~nm}$. El valor del punto de corte (cut-off) para la prueba de ELISA fue determinado como el promedio de 5 controles negativos más 3 veces el valor de la desviación estándar de los mismos. Toda muestra que había obtenido un valor mayor al cut-off fue considerada como positiva.

\section{RESULTADOS}

De un total de 17 pacientes, 16 con equinococosis quística hepática y uno equinococosis quística hepática y pulmonar, quince del sexo femenino y 2 del sexo masculino, con edades entre 25 y 80 años (promedio 58 años), 6 pacientes presentaron quiste único, un paciente dos quistes, dos pacientes tres quistes, dos con cuatro quistes, uno con seis, uno con siete, tres con masas quísticas conteniendo numerosos quis- tes (más de 10) y una paciente además de los seis quistes hepáticos presentaba ocho quistes pulmonares. Por otra parte el número de muestras tomadas postratamiento fluctuó entre dos y siete. Todos estos pacientes fueron atendidos en los consultorios externos del Instituto de Medicina Tropical Daniel A Carrión de la Universidad Nacional Mayor de San Marcos, entre los años 2003 y 2011 (tabla 1).

Los 17 pacientes fueron calificados como curados o con una mejoría mayor al 50\% desde el punto de vista clínico y ultrasonográfico. Además, en 5 pacientes el diagnóstico se hizo utilizando la prueba de ELISA para IgE de hidatidosis y en el resto western blot con tres bandas 8,16 y $21 \mathrm{KDa}$. Pero a todos se les hizo el seguimiento con la determinación de IgE. De los 17 pacientes, en 10 se mantuvieron los niveles de IgE en sangre por debajo del punto de corte, lo que se consideró como evidencia de curación, lo que además coincidía con los cambios en la ecoestructura que iba de CE1 y CE2 a CE4 Y CE5, según la clasificación de la OMS para las imágenes

Tabla 1. Características de los pacientes.

\begin{tabular}{|c|c|c|c|c|c|c|c|c|c|c|c|c|}
\hline \multirow{2}{*}{$\mathrm{N}$} & \multirow{2}{*}{ Paciente } & \multirow{2}{*}{ Edad } & \multirow{2}{*}{ Sexo } & \multirow{2}{*}{$\begin{array}{c}\text { Años } \\
\text { postratamiento }\end{array}$} & \multirow{2}{*}{$\begin{array}{c}\mathrm{N}^{\circ} \\
\text { quistes }\end{array}$} & \multicolumn{7}{|c|}{ Muestra $N^{0}$} \\
\hline & & & & & & $1^{*}$ & 2 & 3 & 4 & 5 & 6 & 7 \\
\hline 1 & RR & 43 & $\mathrm{~F}$ & 5 & 1 & $x$ & $x$ & $x$ & $x$ & & & \\
\hline 2 & VMA & 80 & $\mathrm{M}$ & 5 & 4 & $x$ & $x$ & $x$ & $x$ & $x$ & $x$ & $x$ \\
\hline 3 & MM & 56 & $\mathrm{~F}$ & 12 & 1 & $x$ & $x$ & $x$ & $x$ & $x$ & & \\
\hline 4 & $J C$ & 76 & $\mathrm{~F}$ & 5 & 2 & $x$ & $x$ & $x$ & & & & \\
\hline 5 & $A B$ & 68 & $\mathrm{~F}$ & 7 & 1 & $x$ & $x$ & $x$ & & & & \\
\hline 6 & $\mathrm{RM}$ & 32 & $\mathrm{~F}$ & 8 & múltiples & $x$ & $x$ & $x$ & $x$ & & & \\
\hline 7 & $A R$ & 69 & $F$ & 6 & 4 & $x$ & $x$ & $x$ & $x$ & & & \\
\hline 8 & CLB & 43 & $F$ & 8 & 20 & $x$ & $x$ & & & & & \\
\hline 9 & $\mathrm{NC}$ & 65 & $F$ & 2 & 1 & $x$ & $x$ & $x$ & $x$ & & & \\
\hline 10 & ER & 72 & $\mathrm{~F}$ & 12 & 3 & $x$ & $x$ & & & & & \\
\hline 11 & ROV & 25 & $F$ & 10 & 1 & $x$ & $x$ & & & & & \\
\hline 12 & GCV & 41 & $\mathrm{~F}$ & 4 & 2 & $x$ & $x$ & $x$ & $x$ & & & \\
\hline 13 & MPR & 62 & $\mathrm{~F}$ & 4 & 1 & $x$ & $x$ & $x$ & $x$ & & & \\
\hline 14 & $\mathrm{FL}$ & 74 & $\mathrm{M}$ & 8 & 3 & $x$ & $x$ & $x$ & & & & \\
\hline 15 & $\mathrm{MC}$ & 50 & $\mathrm{~F}$ & 5 & 7 & $x$ & $x$ & & & & & \\
\hline 16 & PET & 57 & $\mathrm{~F}$ & 4 & 1 & $\mathrm{x}$ & $x$ & & & & & \\
\hline 17 & MCap & 74 & $\mathrm{~F}$ & 4 & 6 & $x$ & $x$ & & & & & \\
\hline
\end{tabular}




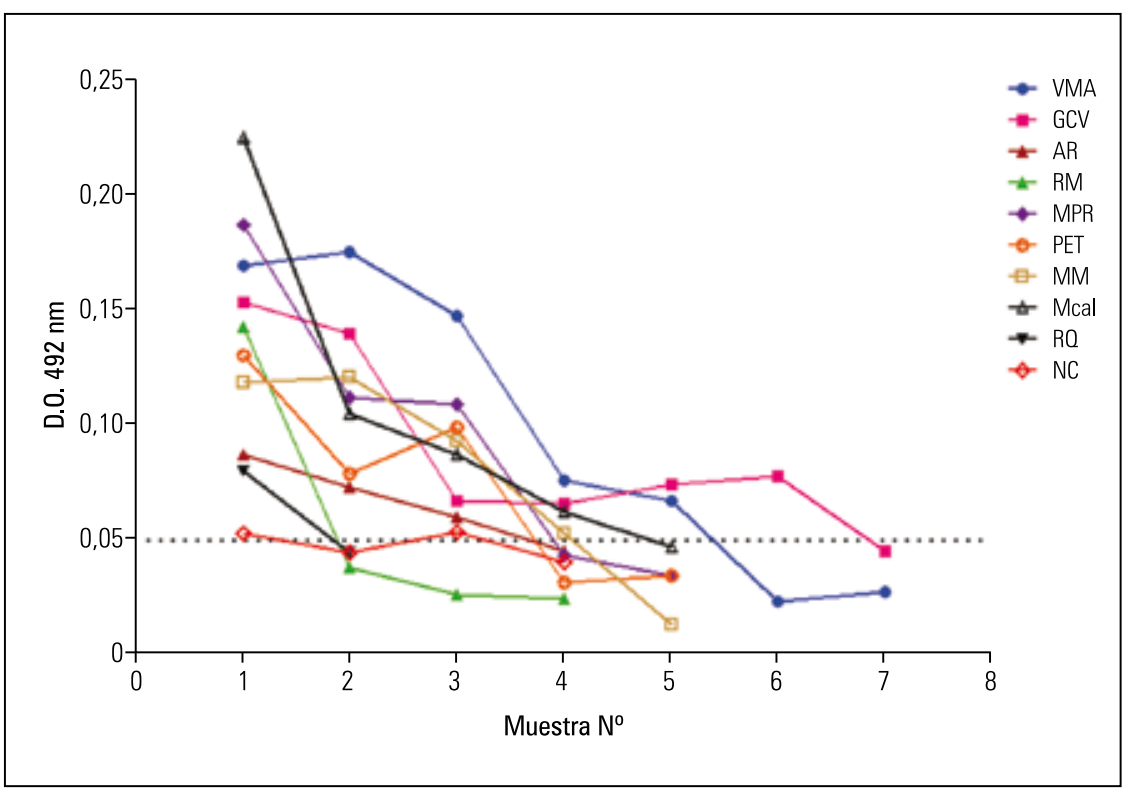

Figura 1. Evolución de los niveles de anticuerpos IgE en pacientes con equinococosis quística tratados con albendazol y que fueron clínica y ecográficamente curados.

ultrasonográficas y que significan en los primeros alta actividad y en los últimos actividad baja o nula (figura 1).

También se pudo evidenciar que aquellos pacientes que al final del tratamiento mostraron evidencia de curación o gran mejoría clínica y ul- trasonográfica y cuyos niveles de $\operatorname{IgE}$ descendieron de manera significativa, en algunos casos por debajo de los niveles de corte, presentaron incremento sostenido de estos niveles como expresión de recurrencia o de aparición de nuevos quistes (figura 2).

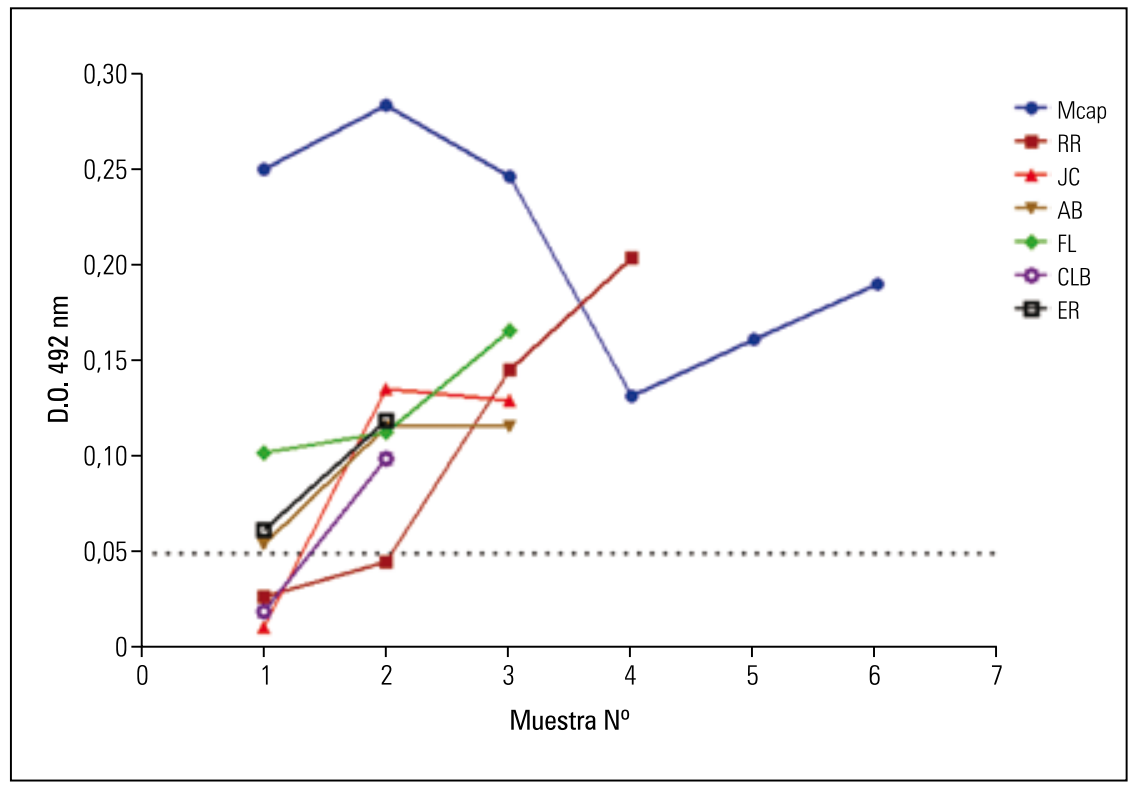

Figura 2. Evolución de los niveles de anticuerpos IgE en pacientes con equinococosis quística tratados con albendazol y que presentaron recurrencia.

\section{DISCUSIÓN}

En un estudio previo de los autores ${ }^{(23)}$ se logró evidenciar la correlación entre la curación clínica y ultrasonográfica y la caída en los niveles de la IgE, en seis pacientes, y en otros cinco se pudo observar que los incrementos de los niveles de $\mathrm{IgE}$ también coincidían con el retorno de los síntomas clínicos y los cambios en la ecoestructura de los quistes o la aparición de nuevos quistes y que se consideraba como recurrencia. En este sentido, fue muy útil la clasificación de la OMS de los quistes hepáticos, que correlacionaba la apariencia ecográfica de los quistes y su grado de actividad ${ }^{(17)}$. En el presente estudio, se aporta cuatro nuevos casos de pacientes curados y dos pacientes más en los que luego de una respuesta muy evidente se produjo una elevación de los niveles de IgE, considerándose como una recurrencia (27-30) (ver figura 2). Como en el estudio anterior, se ha podido comprobar en dos pacientes nuevos la negatividad antes del inicio del tratamiento y su posterior positividad al segundo ciclo de tratamiento, lo que tiene una explicación en el mecanismo de acción de albendazol, que inhibe el ensamblaje de la tubulina en los microtúbulos, de modo que altera la absorción de glucosa a través de la capa germinativa de la pared del quiste. Esto causa depleción de glicógeno y degeneración del retículo endoplásmico y de las mitocondrias de las células de la capa germinal, que resulta en aumento de los lisosomas y subsecuente muerte celular ${ }^{(31)}$ y aumento de la permeabilidad de la membrana quística ${ }^{(32)}$. Ello permite el paso de antígenos hidatídicos al torrente sanguíneo, con la consecuente positivización de las pruebas inmunológicas con la prueba de IgE. Es indudable que este nuevo aporte de cuatro pacientes, si bien todavía no es un número importante desde el punto de vista estadístico, representa una clara tendencia de la utilidad de la prueba, que por otra parte tiene su correlación en otros estudios publicados en diferentes revistas internacionales, como son los casos de Manterola y colaboradores ${ }^{(20)}$ y de Rigano y col ${ }^{(12,20)}$. 
Las pruebas serológicas, como un método para el seguimiento clínico, también tienen la desventaja de que los anticuerpos específicos pueden persistir en el paciente por varios años después de la recuperación ${ }^{(33)}$. Entre las nuevas pruebas serológicas para evaluar si una infección progresará o regresará, las pruebas de isotipos de inmunoglobulinas con el uso de diferentes antígenos del parásito parece un avance razonable ${ }^{(13,34)}$.

También es interesante que se pudo confirmar los resultados obtenidos por otros sobre la eficacia de albendazol en el tratamiento del quiste hidatídico hepático, en porcentajes importantes, considerando las curaciones y mejorías, que incluyen cambios degenerativos en más del $50 \%$ y con 40 a $70 \%$ menor riesgo que el tratamiento quirúrgico y una tasa de recurrencia similar ${ }^{(35-37)}$.

Es evidente que estos resultados contribuyen al objetivo de hacer un seguimiento no solo para comprobar la curación clínica, imagenológica e inmunológica, sino para detectar la recurrencia en una etapa muy temprana, lo que permitirá iniciar un nuevo tratamiento ya sea médico o si las condiciones del paciente y la localización del quiste lo permiten tratamiento quirúrgico, que finalmente es el tratamiento definitivo.

Por otra parte, una exitosa remoción del quiste no es garantía contra la recurrencia, activación de quistes silentes o reinfección. Las tasas de reinfección o recurrencia entre los pacientes tratados quirúrgicamente tiende a ser alto en comunidades donde la infección por Equinococcus granulosus es endémica, estando en el rango de $30 \%$, y los casos recurrentes son frecuentemente inoperables ${ }^{(38)}$. Estas limitaciones al tratamiento quirúrgico en cuanto a la recurrencia o reinfección han motivado que se expanda cada vez más el tratamiento médico con benzimidazoles carbamatos, principalmente albendazol. En ambos casos, uno de los problemas es la dificultad de contar con una herramienta de fácil procesamiento y bajo costo para confirmar en primer lugar la curación de los quistes, especialmente en los casos tratados médicamente, y de mucha importancia el detectar precozmente la recurrencia o la reinfección.

Finalmente, estamos empeñados en continuar realizando esta prueba a todos los nuevos pacientes que padecen de equinococosis quística hepática, con el fin de consolidar este importante método de diagnóstico inmunológico y seguimiento postratamiento, que por otra parte es relativamente sencillo, rápido y de bajo costo, ideal para los pacientes que en general padecen estos problemas médicos, y que son de escasa condición económica.

\section{CONCLUSIONES Y RECOMENDACIONES}

La prueba de ELISA para la detección de anticuerpos IgE de equinococosis quística estandarizada por los autores es una prueba útil para el seguimiento pre y post tratamiento con albendazol, para confirmar la curación clínica y ultrasonográfica de la equinococosis quística hepática. También es útil para la detección temprana de las recurrencias de los pacientes curados o con marcada mejoría.

A la luz de la presente investigación se puede recomendar que esta prueba con excelente sensibilidad y especificidad $(95,7 \%$ y $100 \%$, respectivamente) demostradas en un estudio anterior es la mejor opción para el seguimiento y detección de las recurrencias en los pacientes tratados con albendazol y que se consideran clínica y ultrasonográficamente curados o mejorados.

\section{REFERENCIAS BIBLIOGRÁFICAS}

1. Eckert J, Deplazes P. Biological, epidemiological, and clinical aspects of echinococcosis, a zoonosis of increasing concern. Clin Microbiol Rev. 2004;17(1):107-35

2. Moro PL, Gilman RH, Verastegui M, Bern C, Silva B, Bonilla JJ. Human hydatidosis in Central Andes of Peru: evolution of disease over 3 years. Clinical Infectious dis. 1999 Oct;29(4):807-12.

3. Larrieu E, Belloto A, Arambulu III P, Tamayo $H$. Echinococcosis quística: epidemiologia $y$ control en América del Sur. Parasitol Latinoam. 2004;59:82-9.

4. Salgado S, Suárez-Ognio L, Cabrera R. Características clínicas y epidemiológicas de la equinococcosis quistica registrada en un área endémica en los andes centrales del Perú (1991-2002). Ncootrop Helminthol. 2007;1(2):9-83.

5. Brunetti E, Junghanss T. Update on cystic hydatid disease. Curr Opin Infect Dis. 2009;22(5):497-502.

6. Dziri C, Haouet K, Fingerhut A, Zaouche A. Management of cystic echinococcosis complications and dissemination: where is the evidence? World J Surg. 2009;33(6):1266-73.

7. Stojkovic M, Zwahlen M, Teggi A, Vutova K, Cretu CM, Virdone R, Nicolaidou P, Cobanoglu N, Junghanss $T$. Treatment response of cystic echinococcosis to benzimidazoles: a systematic review. PLoS Negl Trop Dis. 2009;3(9):e524.

8. Teggi A, Lastillo MG, De Rosa F. Therapy of human hydatid disease with mebendazole and albendazole. Antimicrob Agents Chemother. 1993;37:167984

9. Brunetti E, Maiocchi L, Garlaschelli AL, Gulizia R, Filice C. [Overview of therapeutic options for cystic echinococcosis]. Parassitologia. 2004 Jun;46(1-2):53-5.

10. World Health Organization Guidelines for the treatment of cystic and alveolar echinococcosis in humans. Bull WHO. 1996;74:231-42.

11. Todorov T, Georgiev, P, Handjiev S, Vutova K. Potentials of benzimidazole compounds in treatment of human echinococcosis. Arch Intern hidatidosis. 1997;32:164-7. Tropical Medicine \& Parasitology 2005, Vol 99, No 7, 649-65

12. Aceti A, Pennica A, Teggi A, Fondacaro LM, Caferro M, Leri O, Tacchi G, Celestino D, Quaranta G, De Rosa $F$, et al. IgG subclasses in human hydatid disease: prominence of the $\lg 44$ response. Int Arch Allergy Immunol. 1993;102(4):347-51.

13. Riganò R, Profumo E, loppolo S, Notargiacomo S, Ortona E, Teggi A, Siracusano A. Immunological markers indicating the effectiveness of pharmacological treatment in human hydatid disease. Clin Exp Immunol. 1995;102(2):281-5.

14. Dreweck CM, Lüder CG, Soboslay PT, Kern P. Subclass-specific serological reactivity and IgG4specific antigen recognition in human echinococcosis. Trop Med Int Health. 1997; 2(8):779-87.

15. McVie A, Ersfeld K, Rogan MT, Craig PS. Expression and immunological characterization of Echinococcus granulosus recombinant antigen $\mathrm{B}$ for $\lg \mathrm{G} 4$ subclass detection in human cystic echinococcosis. Acta Trop. 1997;67(1-2):19-35.

16. Daeki AO, Craig PS, Shambesh MK. IgG-subclass antibody responses and the natural history of hepatic cystic echinococcosis in asymptomatic patients. Ann Trop Med Parasitol. 2000;94(4):319-28.

17. WHO Informal Working Group. International classificationof ultrasound images in cystic echinococcosis for application inclinical and field epidemiological setting. Acta Tropica. 2003;85:253-61.

18. Lawn SD, Bligh J, Craig PS, Chiodini PL. Human cystic echinococcosis: evaluation of post-treatment serologic follow-up by IgG subclass antibody detection. Am J Trop Med Hyg. 2004;70(3):329-35.

19. Riganò R, loppolo S, Ortona E, Margutti P, Profumo E, Ali MD, Di Vico B, Teggi A, Siracusano A. Longterm serological evaluation of patients with cystic echinococcosis treated with benzimidazole carbamates. Clin Exp Immunol. 2002 Sep;129(3):48592.

20. Khabiri AR, Bagheri F, Assmar M, Siavashi MR. Analysis of specific $\lg E$ and $\lg G$ subclass antibodies 
for diagnosis of Echinococcus granulosus. Parasite Immunol. 2006;28(8):357-66.

21. Manterola C, Vial M, Schneeberger P, Peña JL, Hinostroza J, Sanhueza A. Precision of ELISA-IgE and ELISA-IgG determination in the postoperative follow-up of patients with hepatic echinococcosis. Cir Esp. 2007;81(1):23-7.

22. Lowry OH, Rosebrough NJ, Farr AL, Randall RJ. Protein measurement with the Folin phenol reagent. J Biol Chem. 1951 Nov;193(1):265-75.

23. Vildozola H, Espinoza I, Roldan W. H Estandarización de una prueba de ELISA para detectar anticuerpos $\lg E$ en pacientes con equinococosis quistica y su utilidad en el diagnóstico y seguimiento de pacientes tratados con albendazol: reporte preliminar. An Fac med. 2012;73(1):36-41.

24. Türkyilmaz Z, Sönmez K, Karabulut R, Demirogullari B, Göl H, Basaklar AC, Kale N. Conservative surgery for treatment of hydatyd cysts in children. World $\mathrm{J}$ Surg. 2004 Jun;28(6):597-601.

25. Schipper HG, Kager PA. Diagnosis and treatment of hepatic echinococcosis: an overview.Scand J Gastroenterol Suppl. 2004;241:50-5.

26. Oriol R, Williams JF, Perez Esandi MV, Oriol C. Purification of lipoprotein antigens of Echinococcus granulosus from sheep hydatd fluid. Am J Trop Med Hyg. 1971;20(4):569-74

27. Atmatzidis KS, Pavlidis TE, Papaziogas BT, Mirelis C, Papaziogas TB. Recurrence and long-term outcome after open cystectomy with omentoplasty for hepatic hydatid disease in an endemic area. Acta Chir Belg. 2005 Apr;105(2):198-202.

28. Smego RA Jr, Sebanego P. Treatment options for hepatic cystic echinococcosis. Int J Infect Dis. 2005;9:69-76.

29. Teggi A. An up-to-date on clinical management of human cystic echinococcosis. Parasitologia. 2004;46:405-7.

30. Nahmias J, Goldsmith RS, Soibelman M, el-On J. Three- to 7-year follow-up after albendazole treatment of 68 patients with cystic echinococcosis (hydatid disease). Ann Trop Med Parasitol. 1994 Jun;88(3):295-304.

31. Kern P. Medical treatment of echinococcosis under the guidance of good clinical practice $(\mathrm{GCP} / \mathrm{ICH})$. Parasitol Internat. 2006;5:S273 S282.

32. Morris DL, Chinnery JB, Georgiou G, Stamatakis G, Golematis B. Penetration of albendazol sulphoxide into hydatid cysts. Gut. 1987 Jan;28(1):75-80.

33. Pawlowski ZS. Critical points in the clinical management of cystic echinococcosis: a revised review. En : Andersen FL, Ouhelli H, KachaniM, eds. Compendium on cystic Echinococcosis. Provo: Brigham Young University Print Services. 1997:199-235.

34. Wen H, Craig PS. Immunoglobulin G subclass response in human cystic and alveolar echinococcosis. Am J Trop Med Hyg. 1994;51:741-8.

35. Todorov T, Vutova K, Mechkov G, Petkov D, Nedelkov G, Tonchev Z. Evaluation of response to chemotherapy of human cystic echinococcosis. $\mathrm{Br}$
J Radiol. 1990 Jul;63(751):523-31.

36. French CM. Mebendazol and surgery for human hydatid disease in Turkana. East African Med J. 1984;61:113-9.

37. Todorov T, Vutova K, Donev S, Ivanov A, Katzarov K, Takov D. The types and timing of the degenerative changes seen in the cysts during and after benzidazole treatment of cystic echinococcosis. Ann Trop Med Parasitol. 2005 Oct;99(7):649-59.

38. Bezzi M, Teggi A, De Rosa F, Capozzi A, Tucci G, Bonifacino A, Angelini L. Abdominal hydatid disease: US findings during medical treatment. Radiology. 1987 Jan;162(1 Pt 1):91-5.

Artículo recibido el 12 de junio de 2015 y aprobado para publicación el 10 de julio de 2015.

Conflicto de intereses: Los autores declaran que no existen conflictos de intereses.

Financiamiento: Propio de los autores.

Correspondencia:

Dr. Herman Vildózola Gonzales

Correo electrónico: hvildozolag@unmsm.edu.pe 